\title{
Synergistic antinociceptive effects of alfentanil and propofol in the formalin test
}

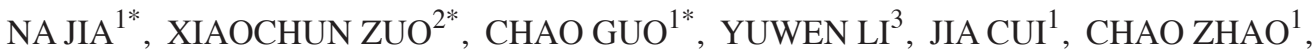 \\ SHANSHAN CAO $^{1}, \mathrm{CHAO} \mathrm{WANG}^{1}, \mathrm{RUILI} \mathrm{LI}^{1}, \mathrm{YIN} \mathrm{WU}^{1}$ and AIDONG WEN ${ }^{1}$ \\ ${ }^{1}$ Department of Pharmacy, Xijing Hospital, Fourth Military Medical University, Xi'an, Shaanxi 710032; \\ ${ }^{2}$ Department of Pharmacy, Shaanxi Province Friendship Hospital, Xi'an, Shaanxi 710068; ${ }^{3}$ Department of Pharmacy, \\ The First Affiliated Hospital of Soochow University, Suzhou, Jiangsu 215006, P.R. China
}

Received November 23, 2015; Accepted December 2, 2016

DOI: $10.3892 / \mathrm{mmr} .2017 .6174$

\begin{abstract}
The present study was conducted to determine the combined analgesic effect of alfentanil and propofol in the formalin test. Diluted formalin was injected into the dorsal surface of the right hind paw in rats. Nociceptive behavior was determined by counting the number of flinches of the injected paw for $1 \mathrm{~h}$ after injection; a reduction in formalin-induced flinching was interpreted as an antinociceptive effect. Isobolographic analysis was used to determine the type of antinociceptive interaction (additivity, antagonism or synergism). Extracellular signal-regulated kinase (ERK) and c-fos protein levels were also detected by western blot analysis to determine the potential mechanisms of the synergistic effect. Alfentanil, propofol or an alfentanil-propofol combination had an antinociceptive effect in the formalin test. The median effective dose $\left(\mathrm{ED}_{50}\right)$, value of the individual drug was also obtained. The derived theoretical $\mathrm{ED}_{50}$ for the antinociceptive effect $(4.36 \mathrm{mg} / \mathrm{kg}$ ) was different from the observed experimental $\mathrm{ED}_{50}$ value $(2.51 \mathrm{mg} / \mathrm{kg})$. The interaction between alfentanil and propofol that produced the antinociceptive effect was synergistic according to isobolographic analysis. Furthermore, the combination of alfentanil and propofol treatments may produce synergistically antinociceptive effects by inhibiting the phosphorylation of ERK1/2 and decreasing the expression of $\mathrm{c}-\mathrm{fos}$ in the spinal cord. These results demonstrated that combined treatment, with alfentanil and propofol, produced synergistic antinociceptive effects in
\end{abstract}

Correspondence to: Dr Yin Wu or Professor Aidong Wen, Department of Pharmacy, Xijing Hospital, Fourth Military Medical University, 127 Changle West Street, Xi'an, Shaanxi 710032, P.R. China

E-mail:wuyin_2005@126.com

E-mail: paperadwen@outlook.com

*Contributed equally

Key words: propofol, alfentanil, formalin test, synergistic antinociceptive effect, extracellular signal-regulated kinase, c-fos the formalin test and may have therapeutic potential for the treatment of acute pain.

\section{Introduction}

Combinations of drugs that have similar effects have been employed clinically. Of the three types of drug interactions that can occur (synergism, additivity and antagonism), synergism is preferred as it allows lower doses of each drug to be used, which reduces the risk of any potential side effects is reduced (1). Clinically, combinations of opioid analgesics and intravenous anesthetics are used to establish balanced anesthesia and to reduce side effects, including earlier recovery and less postoperative nausea and vomiting. Opioids have long been used for the treatment of pain and are one of the most commonly prescribed drugs for pain management. They act through three receptors, termed $\mu, \kappa$ and $\delta$ opioid receptors. Opioid receptors are enabled by endogenously produced peptides, such as morphine, and opioid drugs, including fentanyl. Of these, the $\mu$ opioid receptor has an important role as the mediator of the majority of the effects of most clinically used opioids (2). Alfentanil is a short-acting synthetic opioid analgesic drug that targets $\mu$ opioid receptors and is $\sim 4$-fold faster than fentanyl in terms of the onset of effects (3). Opioid agonists are effective analgesic drugs and are irreplaceable in the treatment of inflammatory and severe pain (4).

Propofol is a widely used intravenous general anesthetic. It is reported to function at a specific site in $\gamma$-aminobutyric acid-A receptors $\left(\mathrm{GABA}_{\mathrm{A}} \mathrm{R}\right)$ and functions as a positive allosteric modulator or an agonist (5). It is indistinct from the analgesic actions of propofol despite its anesthetic effects. Gilron et al (6) reported that propofol reduced hind paw formalin-induced expression of fos-like immunoreactivity in spinal neurons. The results of the study indicated the analgesic effect of propofol. Our previous research demonstrated the analgesic effects of propofol in several animal models (7). Sun et al (8) previously demonstrated the peripheral antinociceptive effect of propofol in an inflammatory pain model.

Extracellular signal-regulated kinase (ERK) is a mitogen-activated protein kinase (MAPK) subfamily member. It is activated in spinal dorsal horn neurons in response to injury and inflammation-induced hyperalgesia of the 
peripheral tissue, with similar results in a murine model of visceral pain $(9,10)$. Furthermore, it is known that c-fos is an immediate early gene and a downstream target of ERK. C-fos is recognized as a marker for stimulus-induced changes in the activity of neurons. It is induced in the central nervous system under various conditions, including in response to inflammatory and painful stimuli (11). ERK and c-fos are expressed in the spinal cord and are important for nociception.

Alfentanil combined with propofol is a promising combination for total intravenous anesthesia. It is well established that propofol and alfentanil synergistically suppress pain in clinical and animal experiments $(7,12)$. However, to the best of our knowledge, no study has investigated the synergistic antinociceptive effects and potential mechanism of alfentanil and propofol on tonic inflammatory pain. The present study proposed that formalin-triggered behavioral responses may be synergistically inhibited by a combination of alfentanil and propofol, and that this would be associated with the ERK and c-fos signaling pathway. The type of interaction (synergism, additivity or antagonism) between alfentanil and propofol was evaluated by isobolographic analysis.

\section{Materials and methods}

Animals. All experiments were performed in adherence with the guidelines for the care and use of laboratory animals (13) and were approved by the Fourth Military Medical University Committee on Animal Care (Xi'an, China). Animal treatments were performed according to the ethical guidelines of the International Association for the Study of Pain (14) for the investigation of experimental pain in conscious animals. Male Sprague Dawley rats $(n=24 ; 7$ weeks, 150-220 g) were obtained from the animal research center at the Fourth Military Medical University. The rats were raised in individual standard cages and maintained on a $12 \mathrm{~h}$ light/dark cycle (lights on at 07:00 a.m.) at $22^{\circ} \mathrm{C}$. Testing was performed during the light cycle. Food and water were available ad libitum. Each animal was restrainer-trained and habituated to the test environment for 1 week prior to testing.

Reagents and antibodies. Alfentanil (cat. no. 20151009; Hubei Gedian Humanwell Pharmaceutical Co., Ltd., Wuhan, China) was suspended in propylene glycol (XiLu Chemical Co., Ltd., Guangzhou, China) and diluted with propofol $(10 \mathrm{mg} / \mathrm{ml}$; cat. no. p028104; diprivan; AstraZeneca, London, UK) to obtain the desired concentrations of the drug. Rabbit p44/42 MAPK (ERK1/2; 137F5) antibody (cat. no. 4695; 1:1,000), rabbit phospho-p44/42 MAPK [phosphorylated ERK1/2 (pERK); Thr202/Tyr204] antibody (cat. no. 4376; 1:1,000) and rabbit c-fos antibody (cat. no. 2250; 1:1,000) were purchased from Cell Signaling Technology, Inc. (Danvers, MA, USA). Unless otherwise stated, all other chemicals were purchased from Sigma-Aldrich (Merck Millipore, Darmstadt, Germany).

Formalin test. The paw formalin test is a well-characterized experimental model of nociception and was performed as described previously (15). Following intraplantar injection of formalin solution $(5 \% ; 50 \mu \mathrm{l})$ into the right hind paw, 24 rats $(\mathrm{n}=6$ per group) were placed in individual clear plastic cages $(22 \times 12 \times 12 \mathrm{~cm})$. Before the start of the experiments, the animals were acclimatized to the laboratory environment for at least one week. Flinching behavior was considered to be an expression of nociception. Time courses of antinociceptive responses resulting from the administration of different drugs were constructed by plotting the mean number of flinches as a function of time. The typical time course of the response to formalin is biphasic, with an early and short-lasting first phase followed, after a quiescent period, by a second, prolonged (tonic) phase. While phase I is considered to reflect acute nociceptive pain due to a direct stimulation of the nerve by formalin, phase II is attributed to the combination of ongoing inflammatory-associated afferent input from peripheral tissue and functional changes in the spinal dorsal horn (central sensitization) (16). Flinching was defined as rapid and brief withdrawal or flexing of the injected paw, lifting, licking and rubbing behavior. The time-response data were presented as the total number of flinches. To determine the ED50 values of each drug, the number of flinches was converted to the percentage of maximum possible effect (\% MPE) according to the formula:

MPE $(\%)=100$-(Sum of flinching count with drug/Sum of control flinching count)x100.

Isobolographic analysis. The up-and-down method was used to determine the median effective analgesic dosages of alfentanil and propofol administered either alone, or in combination. Certain groups of animals ( $n=6$ per group) were treated intravenously with various concentrations of either alfentanil $(5,10$, 20 and $40 \mathrm{mg} / \mathrm{kg}$ ) or propofol $(2.5,5,10$ and $20 \mathrm{mg} / \mathrm{kg}) 10 \mathrm{~min}$ prior to formalin injection. The alfentanil-propofol combination was also administered intravenously at increasing doses $(0.5,1,2$ and $4 \mathrm{mg} / \mathrm{kg})$. Control animals were given saline and were interspersed concurrently with the drug-treated animals. The volumes administered were $4 \mathrm{ml} / \mathrm{kg}$. Rats in all groups were observed for changes in behavior that may have been induced by the treatments. In the present study, the initial dosages of alfentanil and propofol were determined according to preliminary experiments and literature values $(7,17)$. Dose-response curves were constructed using least-squares linear regression using the Pharm Tools Pro software (version no. 1.1.27; The McCary Group, Inc., Lehigh Valley, PA, USA). Following the assessment of antinociception for each drug, experimental median effective dose $\left(E_{50}\right)$ values for each drug were determined. Subsequently, a dose-response curve was obtained by concurrent delivery of alfentanil and propofol in a fixed-ratio mixture (1:150), which was based on the $\mathrm{ED}_{50}$ values of each individual agent. The ratio of the two drugs was obtained from our previous study (18).

To construct the experimental antinociceptive effect-dose curve, each group of rats received one of the following doses of the drug combination: Alfentanil $\operatorname{ED}_{50}(25.3 \mu \mathrm{g} / \mathrm{kg})+$ propofol $\operatorname{ED}_{50}(8.7 \mathrm{mg} / \mathrm{kg})$; alfentanil $\mathrm{ED}_{50} / 2(12.65 \mu \mathrm{g} / \mathrm{kg})+$ propofol $\mathrm{ED}_{50} / 2(4.35 \mathrm{mg} / \mathrm{kg}) ;$ alfentanil $\mathrm{ED}_{50} / 4(6.33 \mu \mathrm{g} / \mathrm{kg})+$ propofol $\mathrm{ED}_{50} / 4(2.18 \mathrm{mg} / \mathrm{kg})$; alfentanil $\mathrm{ED}_{50} / 8(3.17 \mu \mathrm{g} / \mathrm{kg})+$ propofol $\mathrm{ED}_{50} / 8(1.09 \mathrm{mg} / \mathrm{kg})$ or alfentanil $\mathrm{ED}_{50} / 16(1.59 \mu \mathrm{g} / \mathrm{kg})+$ propofol $\mathrm{ED}_{50} / 16(0.55 \mathrm{mg} / \mathrm{kg})$. The experimental $\mathrm{ED}_{50}$ value for the alfentanil-propofol combination was calculated from this curve. For drug combinations, experimental $\mathrm{ED}_{50}\left(\mathrm{ED}_{50 \mathrm{mix}}\right)$ and its associated $95 \%$ confidence 
intervals (CIs) were determined by linear regression analysis of the log dose-response curve and compared with a theoretical additive $\mathrm{ED}_{50}\left(\mathrm{ED}_{50 \text { add }}\right)$ obtained from the calculation: $\mathrm{ED}_{50 \text { add }}=\mathrm{fxED}_{50 \text { alfentanil }}+(1-\mathrm{f}) \mathrm{xED}_{50 \text { propofol }}$, where $\mathrm{f}$ denotes a fraction of the corresponding $\mathrm{ED}_{50}$ in drug mixture (in the present study, $\mathrm{f}=0.5)$. In this equation $(17,18), \mathrm{ED}_{50 \text { add }}$ is the total dose, and the variance of $\mathrm{ED}_{50}$ add was calculated as follows: $\operatorname{Var} \mathrm{ED}_{50 \text { add }}=\mathrm{f}^{2} \mathrm{x}$ Var $\mathrm{ED}_{50 \text { alfentanil }}+(1-\mathrm{f})^{2} \mathrm{x}$ Var $\mathrm{ED}_{50 \text { propofol }}$.

From these variances, CIs were calculated and resolved according to the ratio of the individual drug in the combination. When the drug combination gives an experimental $\mathrm{ED}_{50}$ not statistically different from the theoretical calculated $\mathrm{ED}_{50}$, the combination has an additive effect. If the mixture $\mathrm{ED}_{50}$ lies on the theoretical additive $\mathrm{ED}_{50}$ line, or the confidence intervals overlap that line, then the mixture is considered to be additive. If the mixture $\mathrm{ED}_{50}$ lies below the theoretical additive $\mathrm{ED}_{50}$ line and the confidence intervals do not overlap that line, the mixture is considered to be synergistic. The theoretical and experimental $\mathrm{ED}_{50}$ values of the combinations were also contrasted by calculating the interaction index $(\gamma)$. This was calculated as $\mathrm{ED}_{50 \text { mix }} / \mathrm{ED}_{50 \text { add }}$. If the value is $\sim 1$, the interaction is additive. Values $<1$ are an indication of the magnitude of supra-additive or synergistic interactions, and values $>1$ correspond to sub-additive or antagonistic interactions (19-22).

Protein preparation and measurement. The behavioral test was performed on the following 5 groups of rats following formalin injection $(5 \% ; 50 \mu \mathrm{l} ; \mathrm{n}=6$ per group): Group FA (rats received formalin and an equal volume of saline vehicle); group Alf (rats received formalin and alfentanil at dose of $25.3 \mu \mathrm{g} / \mathrm{kg}$ ); group Pro (rats received formalin and propofol at dose of $8.7 \mathrm{mg} / \mathrm{kg}$ ); group Alf + Pro (rats received formalin, alfentanil-propofol combination at dose of $2.51 \mathrm{mg} / \mathrm{kg}$ ); control group rats received an equal volume of saline vehicle only. The dosage of alfentanil or propofol alone was $\mathrm{ED}_{50}$. The dosages of combination of alfentanil and propofol were $\mathrm{ED}_{5}$.

To evaluate pERK protein levels, rats were sacrificed 30 min after drug treatment. For the measurement of c-fos protein expression, rats were sacrificed $60 \mathrm{~min}$ after drug treatment. Rats were anesthetized intraperitoneally with $40 \mathrm{mg} / \mathrm{kg}$ sodium pentobarbital, and perfused with fresh $4 \%$ paraformaldehyde in $0.1 \mathrm{M}$ phosphate buffer ( $\mathrm{pH} 7.4$ ). Following decapitation, after a brief $20 \mathrm{sec}$ exposure to $\mathrm{CO}_{2}$, rat spinal cord L5-L6 segments were excised, spinal meninges removed and tissue dissociated mechanically, and stored at $-80^{\circ} \mathrm{C}$ until detection. Tissue samples were homogenized by using a Polytron handheld homogenizer (Kinematica, Luzern, Switzerland) in lysis buffer (50 mM Tris-HCl; $150 \mathrm{mM} \mathrm{NaCl}$; 2 mM EDTA; $10 \%$ glycerol; $1 \%$ Triton X-100; 1\% Igepal CA-630; $1 \%$ sodium deoxycholic acid). After 30 min incubation, homogenates were centrifuged at $12,000 \mathrm{x} g$ for $15 \mathrm{~min}$ at $4^{\circ} \mathrm{C}$. Supernatants were then collected and stored at $-80^{\circ} \mathrm{C}$ until used. Total protein content was determined using a Bradford kit from Bio-Rad Laboratories, Inc. (Hercules, CA, USA).

Western blot analysis. Western blot assay was performed as previously described (21). Aliquots of total protein samples $(50 \mu \mathrm{g})$ were separated on a $10 \%$ SDS-PAGE gel and transferred onto a nitrocellulose membrane. The filter membranes were blocked with $5 \%$ non-fat milk for $1 \mathrm{~h}$ at room temperature and incubated with the primary antibody specific for pERK1/2 or total ERK1/2 (1:1,000 dilution) and c-Fos (1:1,000 dilution). The membrane was washed with $0.05 \%$ TBS Tween buffer and incubated for $1 \mathrm{~h}$ with the secondary antibody conjugated with horseradish peroxidase (Goat anti-horseradish peroxidase; cat. no. 123-005-021, 1:1,000; Jackson ImmunoResearch Laboratories, Inc., West Grove, PA, USA) for $1 \mathrm{~h}$ at room temperature and visualized in ECL solution (cat. no. 1705060; Bio-Rad Laboratories, Inc., Hercules, CA, USA). for $1 \mathrm{~min}$, followed by film exposure for 1-10 min. The loading and blotting of equal amounts of proteins were verified by re-probing the membrane with antibody against $\beta$-actin (1:1,000; cat. no. sc-47778, Santa Cruz Biotechnology, Inc., Dallas, TX, USA). The intensity of each immunoblot assay band was quantified using a VersaDoc Imaging System (Bio-Rad Laboratories, Inc.). The experiments were repeated twice. Quantification of immunoreactivity corresponding to the total and phosphorylated bands was performed by densitometric analysis using Multi Gauge Version 3.0 (Fujifilm, Tokyo, Japan).

Statistical analysis. Results were presented as the mean \pm standard error of the mean or as $\mathrm{ED}_{50}$ values with $95 \% \mathrm{CIs}$. The statistical significance of dose-responses was determined by one-way analysis of variance followed by the Tukey's post hoc test. Isobolographic calculations were performed by using the Pharm Tools Pro software (version no. 1.1.27, The McCary Group, Inc.). Statistical analysis of the isobolograms was performed as previously described (22) and differences between experimental and theoretical values were assessed by Student's unpaired t-test. $\mathrm{P}<0.05$ was considered to indicate a statistically significant difference.

\section{Results}

Antinociceptive effect of alfentanil and propofol. Plantar injection of formalin produces nociceptive behavior, including flinches of the paw. Flinching was defined as rapid and brief withdrawal or flexing of the injected paw, lifting, licking and rubbing behavior. In the present study, the number of pain responses in $5 \mathrm{~min}$ intervals during phase I, for $20 \mathrm{~min}$, and 10 min intervals during phase II, for $40 \mathrm{~min}$, following formalin injection was recorded. Saline-treated control rats exhibited discrete biphasic behavioral responses consisting of an early short-lasting response (phase I, 0-10 min post-injection), followed by a late, prolonged response (phase II, $16-60 \mathrm{~min}$ post-injection). The duration of licking, lifting and rubbing were considered to be nociceptive behaviors in the formalin model. The mean number of flinches peaked around 0-10 min and 30-50 min after formalin intraplantar injection, which was followed by a gradual decline in all groups (Fig. 1A). Nociceptive behavior, the mean number of flinches, between saline and drug-treated groups was compared. There were no significant differences between any of the groups during phase II of the behavioral response. However, the amount of licking and lifting behavior was reduced in the alfentanil or propofol alone groups, and alfentanil-propofol combination group for the first $5 \mathrm{~min}$ after formalin injection, compared with the saline group during phase $\mathrm{I}(\mathrm{P}<0.05$; Fig. $1 \mathrm{~A})$. The total numbers of flinches during phase I and phase II following 


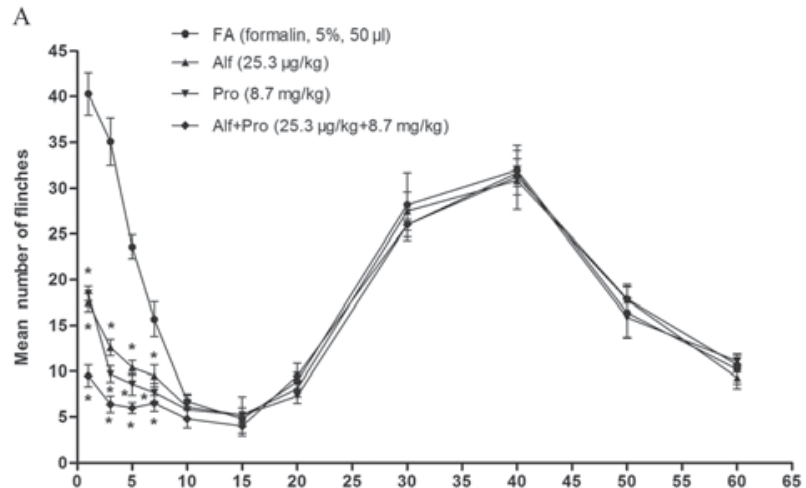

B

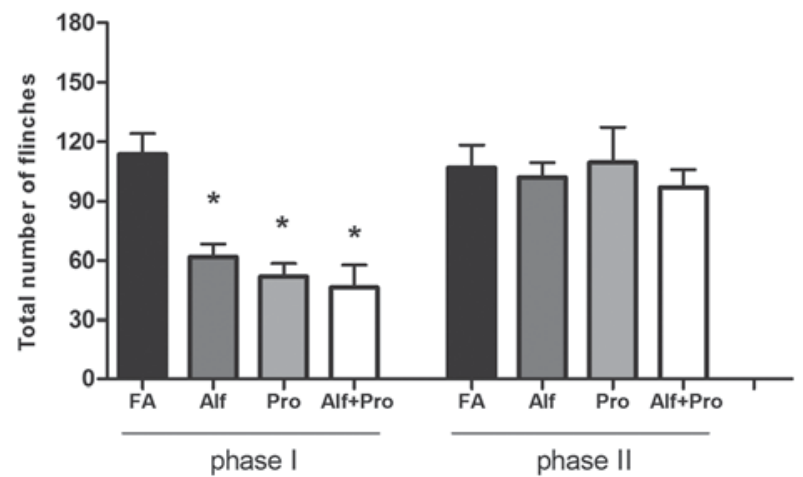

Figure 1. Effects of alfentanil, propofol and a combination of alfentanil and propofol on the mean number of flinches following intraplantar injection of formalin into the hind paw of rats. The behavioral test was performed on the following 5 groups of rats following formalin injection $(5 \% ; 50 \mu 1$; $\mathrm{n}=6$ per group): Group FA (rats received formalin and an equal volume of saline vehicle); group Alf (rats received formalin and alfentanil at dose of $25.3 \mu \mathrm{g} / \mathrm{kg}$ ); group Pro (rats received formalin and propofol at dose of $8.7 \mathrm{mg} / \mathrm{kg}$ ); group Alf + Pro (rats received formalin and alfentanil-propofol combination at dose of $2.51 \mathrm{mg} / \mathrm{kg}$ ); control group rats received an equal volume of saline vehicle only. (A) Effects of intravenous administration of different drugs on the mean number of flinches following formalin injection. (B) Total number of flinches during phase I and II of the nociceptive behavioral response. Alfentanil and propofol treatment, alone and in combination, led to significant antinociceptive effects during phase I of the response. Each point represents the mean \pm standard deviation ( $n=6$; $\mathrm{P}<0.05$ vs. FA group). FA, formalin only group; Alf, alfentanil; Pro, propofol.

formalin injection in the saline treatment group was $121.4 \pm 8.8$ and $100.5 \pm 12.1$, respectively. However, compared with the saline treatment group, the total number of flinches was significantly decreased in groups Alf (56.1 \pm 5.3$)$, Pro (50.3 \pm 5.0$)$ and Alf + Pro (33.2 \pm 4.6$)$ during phase I $(\mathrm{P}<0.05$; Fig. 1B). There were no significant differences between any of the groups during phase II.

Isobolographic analysis for drug combination. In phase I, alfentanil, propofol and alfentanil-propofol combination groups led to a dose-dependent antinociceptive effect. Linear regressions for alfentanil $(\mathrm{Y}=186.0 \mathrm{X}-24.7$; $\left.\mathrm{R}^{2}=0.9861\right)$, propofol $\left(\mathrm{Y}=153.7 \mathrm{X}-10.92 ; \mathrm{R}^{2}=0.9728\right)$ and co-administration $\left(\mathrm{Y}=91.97 \mathrm{X}+8.55 ; \mathrm{R}^{2}=0.9962\right)$ were calculated by plotting MPE (\%) against the log dose (Fig. 2). The $\mathrm{ED}_{50}$ of individual administration of alfentanil and propofol were $25.3 \pm 2.21 \mu \mathrm{g} / \mathrm{kg}$ and $8.7 \pm 1.344 \mathrm{mg} / \mathrm{kg}$, respectively (Table I). The isobologram was constructed by connecting the $\mathrm{ED}_{50}$ of alfentanil on the abscissa with the $\mathrm{ED}_{50}$ of propofol on the ordinate to obtain the additive line (Fig. 3).
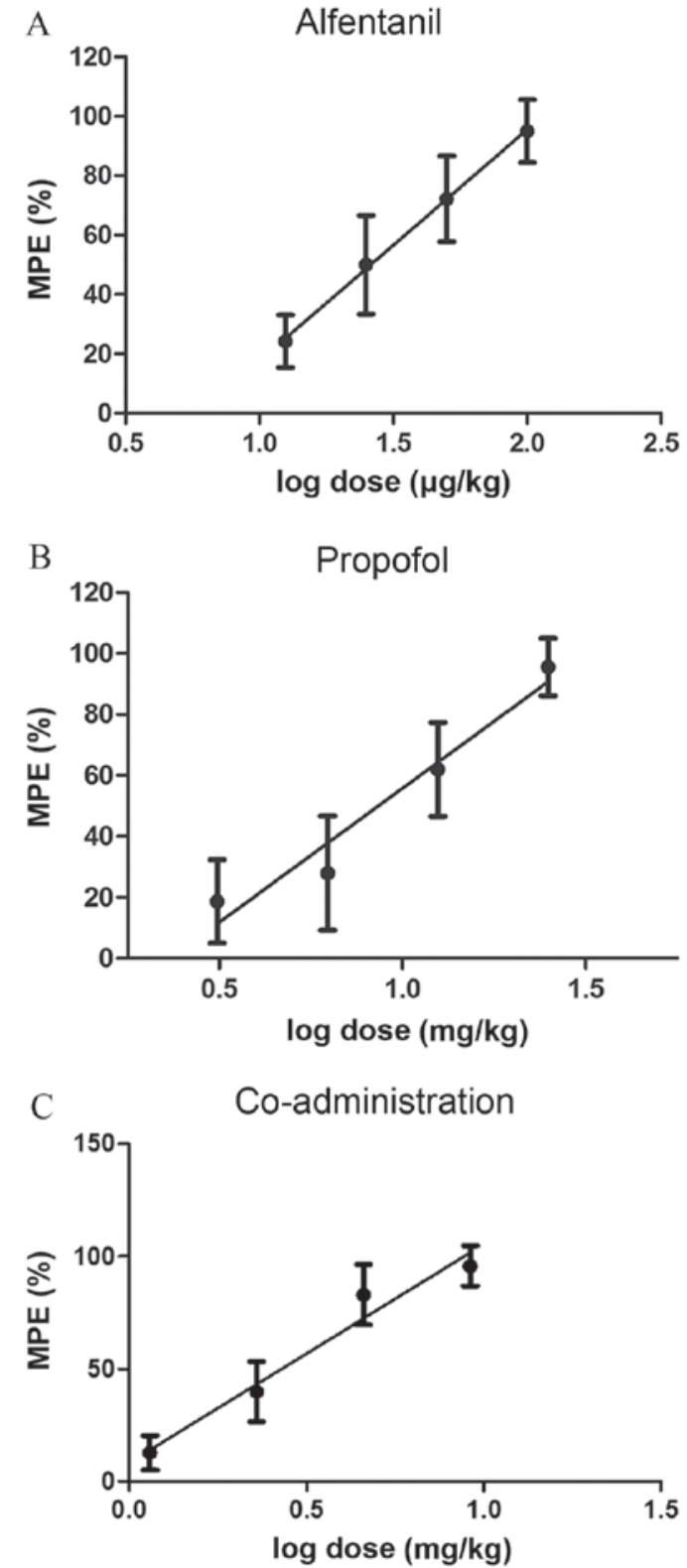

Figure 2. Log dose-response curves for antinociception, at the time of peak effects in the formalin test, induced by different drug treatments. (A) Alfentanil only treatment, linear regression: $Y=186.0 X-24.7\left(R^{2}=0.9861\right)$. (B) Propofol only treatment, linear regression: $\mathrm{Y}=153.7 \mathrm{X}-10.92\left(\mathrm{R}^{2}=0.9728\right)$. (C) Alfentanil-propofol combination treatment, linear regression: $\mathrm{Y}=91.97 \mathrm{X}$ $+8.55\left(\mathrm{R}^{2}=0.9962\right)$. MPE, maximum possible effect.

For the drug combination, the $\mathrm{ED}_{50 \text { mix }}$ and the $95 \% \mathrm{CI}$ of the mixture were computed by linear regression of the $\log$ dose-response curve. The $\mathrm{ED}_{50 \text { mix }}$ and $\mathrm{ED}_{50 \text { add }}$ were plotted in the isobologram (Fig. 3). The fixed drug-dose ratio based on mass quantity for alfentanil and propofol is 1:344. The total $\mathrm{ED}_{50 \text { mix }}$ for the alfentanil-propofol combination is $2.51 \pm 0.56 \mathrm{mg} / \mathrm{kg}$ (Table I), representing $7.27 \mu \mathrm{g} / \mathrm{kg}$ alfentanil and $2.50 \mathrm{mg} / \mathrm{kg}$ propofol. By isobolographic analysis, the $\mathrm{ED}_{50 \text { add }}=4.36 \mathrm{mg} / \mathrm{kg}\left[\left(0.5 \mathrm{xED}_{50}\right.\right.$ alfentanil $)+\left(0.5 \mathrm{xED}_{50}\right.$ propofol)] (Table I), representing $12.64 \mu \mathrm{g} / \mathrm{kg}$ alfentanil plus $4.35 \mathrm{mg} / \mathrm{kg}$ propofol. The $\mathrm{ED}_{50 \text { mix }}$ was $<\mathrm{ED}_{50 \text { add }}$ (Table $\mathrm{I}$ ). The $\gamma$ value was 0.57 , which suggests a synergistic interaction between alfentanil and propofol during phase I of the formalin test (Table I). 
Table I. $\mathrm{ED}_{50}$ and interaction index of alfentanil, propofol, and alfentanil-propofol combination in the formalin test in rats.

\begin{tabular}{lcccc}
\hline Drug group & $\mathrm{ED}_{50}$ (confidence limits) & $\mathrm{ED}_{50 \text { add }}$ & $\mathrm{ED}_{50 \text { mix }}$ & $\gamma$ \\
\hline Alfentanil $(\mu \mathrm{g} / \mathrm{kg})$ & $25.31 \pm 2.21(23.11-27.51)$ & $\mathrm{NA}$ & $\mathrm{NA}$ & $\mathrm{NA}$ \\
Propofol $(\mathrm{mg} / \mathrm{kg})$ & $8.73 \pm 1.34(7.36-10.04)$ & $\mathrm{NA}$ & $\mathrm{NA}$ & NA \\
Alfentanil + propofol $(\mathrm{mg} / \mathrm{kg})$ & $\mathrm{NA}$ & 4.36 & $2.51 \pm 0.56^{\mathrm{a}}$ & 0.57
\end{tabular}

${ }^{a} \mathrm{P}=0.03$ between $\mathrm{ED}_{50}$ add and $\mathrm{ED}_{50 \text { mix }}$ in corresponding nociceptive model indicates a synergistic interaction. $\mathrm{ED}_{50}$ values were obtained following intravenous drug/drug combination administration in the formalin test. $\mathrm{ED}_{50}=$ Effective dose required to produce $50 \%$ antinociceptive activity. $\gamma=\mathrm{ED}_{50 \text { alfentanil combined with propofol }} / \mathrm{ED}_{50}$ alfentanil given alone $+\mathrm{ED}_{50 \text { alfentanil combined with propofol }} / \mathrm{ED}_{50 \text { propofol given alone }}$. Values $\sim 1$ indicate additive interaction, values $>1$ indicate an antagonistic interaction and values $<1$ indicate a synergistic interaction. $\mathrm{ED}_{50}$, median effective dose; SEM, standard error of the mean; $\mathrm{ED}_{50 \text { add }}$, theoretical additive $\mathrm{ED}_{50}$ for drug mixture; $\mathrm{ED}_{50 \text { mix }}$, experimental $\mathrm{ED}_{50}$ for drug mixture; $\gamma$, interaction index; $\mathrm{NA}$, not applicable.

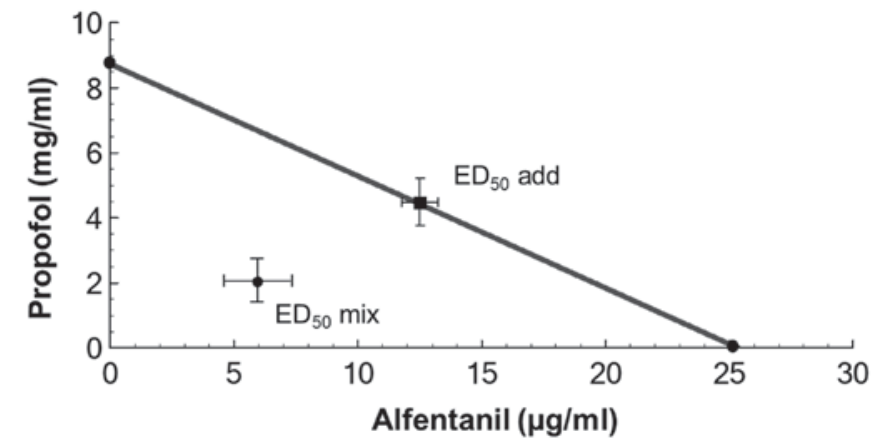

Figure 3. Isobologram for alfentanil-propofol combination treatment in the formalin test. The $\mathrm{ED}_{50}$ values for each drug are plotted at the axes. The straight line that connects each $\mathrm{ED}_{50}$ value is the theoretical additive line and the point highlighted on this line is the $\mathrm{ED}_{50}$ add . There is a significant difference $(\mathrm{P}=0.02)$ between the $\mathrm{ED}_{50 \text { add }}$ and the $\mathrm{ED}_{50 \text { mix }}$, calculated by Student's $t$-test, indicating a synergistic drug interaction between alfentanil and propofol when co-administered. $\mathrm{ED}_{50}$, median effective dose; $\mathrm{ED}_{50}$ add theoretical additive $\mathrm{ED}_{50} ; \mathrm{ED}_{50 \text { mix }}$, experimental $\mathrm{ED}_{50}$.

Effects of alfentanil-propofol combination on ERK and c-fos expression. The expression of total and phosphorylated-ERK (Fig. 4), and c-fos (Fig. 5) in control and drug-treated groups was detected. Compared with the $\beta$-actin bands, the ratios of the optical density of total ERK bands in all groups were not significantly different. To investigate the expression level of the two proteins, the ratio of the optical density of each band for phosphorylated and total proteins were detected, and values were normalized as a percentage of the control group. The effect of drug treatment on total and pERK expression was determined in spinal cord L4-L5 segments of the lumbar enlargement, areas that are involved in the transmission of nociceptive inputs and the control of sympathetic outflow (23). In the present study, two bands, p42 and p44, represented ERK and were analyzed. Concerning ERK activation, there was no significant change in the expression of total-ERK following formalin addition (Fig. 4). However, formalin induced the activation of pERK, which was significantly reduced when subsequently treated with alfentanil $(\mathrm{P}=0.02)$ or propofol $(\mathrm{P}=0.03)$ alone, or combination treatment $(\mathrm{P}=0.01)$, compared with the formalin only group (FA). Furthermore, formalin-induced activation was significantly reduced by combination treatment (Pro + Alf) compared with those treated with propofol $(\mathrm{P}=0.01)$ or alfentanil $(\mathrm{P}=0.03)$ only groups (Fig. 4). The current study subsequently investigated whether propofol and alfentanil had any effect on basal levels of c-fos expression. As illustrated in Fig. 5, there was a clear increase in the expression of c-fos following injection of formalin, highlighted in the FA group. This increased the level of c-fos expression was then significantly reduced when treated with alfentanil $(\mathrm{P}=0.02)$, propofol $(\mathrm{P}=0.02)$ or combination treatment $(\mathrm{P}=0.03)$ compared with the FA group. Notably, the Alf+Pro group also exhibited significantly decreased c-fos expression when compared with treatment with alfentanil $(\mathrm{P}=0.01)$ or propofol $(\mathrm{P}=0.02)$ alone (Fig. 5).

\section{Discussion}

The major finding of the current study was that the combination of alfentanil and propofol led to synergistic antinociceptive effects in the formalin test. Subcutaneous hind paw injection of formalin triggers biphasic nociceptive responses. While phase I is considered to reflect acute nociceptive pain due to direct stimulation of the nerve by formalin, phase II is attributed to the combination of ongoing inflammatory-associated afferent input from peripheral tissue and functional changes in the spinal dorsal horn (central sensitization) (24). Accordingly, the present study investigated the inhibitory effects of alfentanil or propofol on the number of flinches in a given time following formalin injection, flinches were considered to indicate a nociceptive response. Injection of formalin led to persistent inflammatory pain throughout the test. The current study observed that nociceptive behavior during phase I, but not phase II, was reduced when treated with alfentanil, propofol or both. Furthermore, it was established that combined treatment with alfentanil and propofol led to synergistic antinociceptive effects. The present study calculated the $\mathrm{ED}_{50 \text { mix }}$ of the alfentanil-propofol combination in phase I of the formalin test. The $\mathrm{ED}_{50}$ for treatment with alfentanil or propofol alone were calculated as $25.3 \pm 2.21 \mu \mathrm{g} / \mathrm{kg}$ and $8.7 \pm 1.344 \mathrm{mg} / \mathrm{kg}$, respectively. The $\mathrm{ED}_{50 \text { mix }}$ was significantly less than their corresponding $\mathrm{ED}_{50 \text { add }}$, and the calculated interaction index $(\gamma)$ was $<1$. The results of this study initially demonstrated the synergistic interaction between alfentanil and propofol in the formalin test. Notably, the $\mathrm{ED}_{50}$ of propofol in the formalin test was less than its $\mathrm{ED}_{50}$ for clinical application, suggesting that the synergistic antinociceptive effect may potentially be beneficial for its use in clinic for pain treatment. 
$\mathbf{A}$

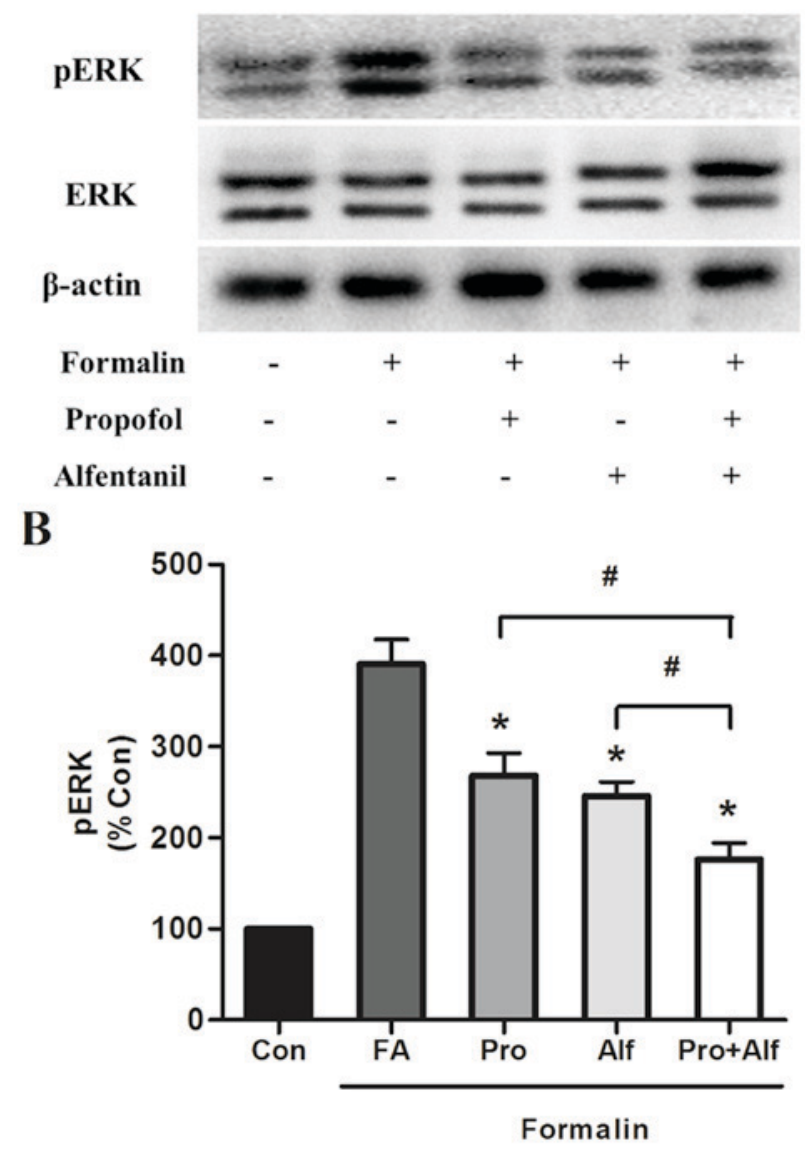

Figure 4. Western blot analysis of ERK and pERK expression in various treatment groups following formalin injection. (A) Western blot of ERK and pERK expression across various treatment groups. There was no change in the expression of total-ERK following formalin administration. (B) Densitometric analysis of the expression of pERK across various treatment groups. The level of each protein was expressed as a percentage of the control. The formalin-induced activation of pERK was significantly reduced by alfentanil, propofol and combined treatment, compared with the FA group. Formalin-induced activation of pERK was also significantly reduced by co-treatment with alfentanil and propofol when compared with Alf and Pro groups. ( $\mathrm{P}<0.05$ vs. FA group; ${ }^{*} \mathrm{P}<0.05$, comparison indicated by brackets). ERK, extracellular signal-regulated kinase; pERK, phosphorylated ERK; Con, control; FA, formalin only group; Alf, alfentanil; Pro, propofol.

A previous study reported that propofol at sub-hypnotic dosage $(0.25 \mathrm{mg} / \mathrm{kg})$ reduced acute pain induced by argon laser stimulation in humans (24). Furthermore, a study that involved healthy volunteers suggested that propofol delivered intravenously, at $0.25 \mathrm{mg} / \mathrm{kg}$ followed by $25 \mu \mathrm{g} / \mathrm{kg} / \mathrm{min}$ or more, led to a reduction in pain intensity (25). Additionally, another study demonstrated that intravenously administered propofol $(0.25-0.5 \mathrm{mg} / \mathrm{kg})$ depressed pain induced by tibial pressure algesimetry in patients who had been through gynecologic surgery (26). However, one study concluded that propofol $(0.5 \mathrm{mg} / \mathrm{kg})$ did not affect thermal pain detection thresholds (27). In the current study, the $\mathrm{ED}_{50}$ of propofol was calculated to be $8.7 \pm 1.344 \mathrm{mg} / \mathrm{kg}$ in a formalin test performed on rats. Propofol is a commonly used intravenous general anesthetic that acts on $G_{A B A} R$ and enhances the action of GABA. It is indistinct from the analgesic actions of propofol despite its profound anesthetic
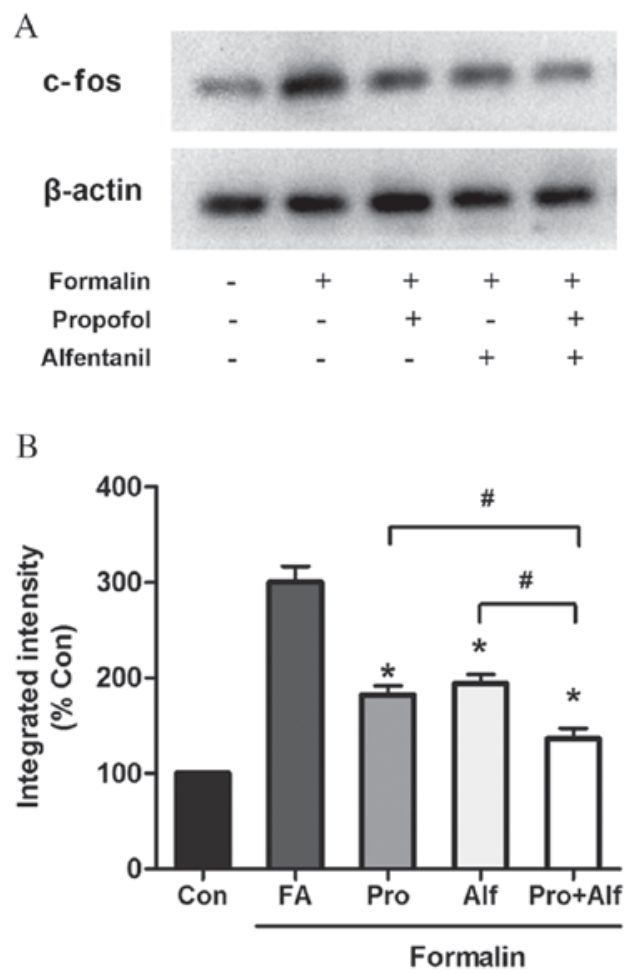

Figure 5. Western blot analysis of c-fos expression in various treatment groups following formalin injection. (A) Western blot of c-fos expression across various treatment groups. (B) Densitometric analysis of the expression of c-fos across various treatment groups. The level of each protein was expressed as a percentage of the control. Increased expression of c-fos was observed following formalin injection. The increased expression level of c-fos was significantly decreased following alfentanil, propofol or combined treatment, compared with the FA group. Combined treatment also reduced the expression of c-fos significantly compared with expression in groups treated with alfentanil or propofol alone. ${ }^{*} \mathrm{P}<0.05$ vs. FA group; ${ }^{*} \mathrm{P}<0.05$, comparison indicated by brackets). Con, control; FA, formalin only group; Alf, alfentanil; Pro, propofol.

effects. Goto et al (28) concluded that propofol had no effect on phase II nociceptive behavioral responses induced by formalin injection in the hind paw of rats. However, Gilron et al (6), reported that propofol reduced hind paw formalin-induced expression of fos-like immunoreactivity in spinal neurons. Their results indicated the analgesic effect of propofol. Antinociceptive effects of propofol have previously been reported in humans (24). It is suggested, based on in vivo studies, that propofol reduced pain in rats via spinal $\mathrm{GAB}_{\mathrm{A}} \mathrm{ARs}(29,30)$. Alfentanil is an analgesic that acts as an agonist of $\mu$ opioid receptors and it is used to relieve acute pain or the severe, chronic and disabling pain associated with terminal conditions, including cancer and degenerative conditions, which include rheumatoid arthritis. The analgesic effects of alfentanil and propofol are regulated through different receptors at the level of the spinal cord. However, the synergistic antinociceptive effects of their combined treatment and the underlying molecular mechanisms of alfentanil and propofol in acute nociceptive pain remain unclear. The current study demonstrated that the synergistic antinociceptive action of alfentanil and propofol in the formalin test is regulated by ERK1/2 and c-fos, as described above (Figs. 4 and 5) (9,10). Further studies are required to investigate the mechanism in further detail. 
In summary, the present research suggests synergism between alfentanil and propofol. These results provide evidence for the potential benefits that the development of synergistic drug combinations of opioid analgesics with intravenous anesthetics may have if applied clinically. The combination of alfentanil with propofol may prove beneficial for the treatment of pain, including neuropathic or anti-inflammatory disease. Furthermore, the combination of alfentanil and propofol treatments may produce synergistically antinociceptive effects through inhibition of pERK1/2 and decreased expression of $\mathrm{c}$-fos in the spinal cord.

\section{Acknowledgements}

This study was financially supported by grants from the National Nature Science Foundation of China (grant no. 81403159) and the National New Drug 'R\&D' project (grant no. 2011ZXJ09302).

\section{References}

1. Hendrickx JF, Eger EI II, Sonner JM and Shafer SL: Is synergy the rule? A review of anesthetic interactions producing hypnosis and immobility. Anesth Analg 107: 494-506, 2008.

2. Kieffer BL and Evans CJ: Opioid receptors: From binding sites to visible molecules in vivo. Neuropharmacology 56 (Suppl 1): S205-S212, 2009.

3. Hug CC, Chaffman M, Camu F and Spierdijk J: Alfentanil: Pharmacology and uses in anaesthesia. Adis, 1984.

4. Taylor BK, Peterson MA, Roderick RE, Tate J, Green PG, Levine JO and Basbaum AI: Opioid inhibition of formalin-induced changes in plasma extravasation and local blood flow in rats. Pain 84: 263-270, 2000.

5. Smith I, White PF, Nathanson M and Gouldson R: Propofol. An update on its clinical use. Anesthesiology 81: 1005-1043, 1994.

6. Gilron I, Quirion R and Coderre TJ: Pre- versus postinjury effects of intravenous GABAergic anesthetics on formalin-induced Fos immunoreactivity in the rat spinal cord. Anesth Analg 88: 414-420, 1999

7. Wu Y, Jia N, Zhao C, Li Y, Shi XP, Li YW, Wang C, Li RL, Wang JW and Wen AD: Synergistic antinociception of propofol-alfentanil combination in mice. Pharmacol Biochem Behav 116: 25-29, 2014.

8. Sun YY, Li KC and Chen J: Evidence for peripherally antinociceptive action of propofol in rats: Behavioral and spinal neuronal responses to subcutaneous bee venom. Brain Res 1043: 231-235, 2005.

9. Ji RR, Befort K, Brenner GJ and Woolf CJ: ERK MAP kinase activation in superficial spinal cord neurons induces prodynorphin and NK-1 upregulation and contributes to persistent inflammatory pain hypersensitivity. J Neurosci 22: 478-485, 2002.

10. Hunt SP, Pini A and Evan G: Induction of c-fos-like protein in spinal cord neurons following sensory stimulation. Nature 328: 632-634, 1987

11. Morgan JI and Curran T: Stimulus-transcription coupling in neurons: Role of cellular immediate-early genes. Trends Neurosci 12: 459-462, 1989.
12. Vuyk J, Engbers FH, Burm AG, Vletter AA, Griever GE, Olofsen E and Bovill JG: Pharmacodynamic interaction between propofol and alfentanil when given for induction of anesthesia. Anesthesiology 84: 288-299, 1996.

13. Vogel HG, et al: Guidelines for the care and use of laboratory animals. In: Drug Discovery and Evaluation. Springer Berlin Heidelberg, pp2023-2037, 2007.

14. Wood MM and Cousins MJ: Iatrogenic neurotoxicity in cancer patients. Pain 39: 1-3, 1989.

15. Cho IH, Chung YM, Park CK, Park SH, Lee H, Kim D, Piao ZG, Choi SY, Lee SJ, Park K, et al: Systemic administration of minocycline inhibits formalin-induced inflammatory pain in rat. Brain Res 1072: 208-214, 2006.

16. Tjølsen A, Berge OG, Hunskaar S, Rosland JH and Hole K: The formalin test: An evaluation of the method. Pain 51: 5-17, 1992.

17. Guindon J, LoVerme J, Piomelli D and Beaulieu P: The antinociceptive effects of local injections of propofol in rats are mediated in part by cannabinoid CB1 and CB2 receptors. Anesth Analg 104: 1563-1569, 2007.

18. Jia N, Zhao C, Wang L, Li Y, Cui J, Cao S, Li R, Wang C, Wu Y and Wen A: The effects of a propofol/alfentanil admixture on total intravenous anaesthesia in dogs undergoing splenectomy. Veterinární Medicína 60: 194-201, 2015.

19. Tallarida RJ, Stone DJ Jr and Raffa RB: Efficient designs for studying synergistic drug combinations. Life Sci 61: PL417-PL425, 1997.

20. Tomić MA, Vucković SM, Stepanović-Petrović RM, Ugresić ND, Prostran MS and Bosković B: Synergistic interactions between paracetamol and oxcarbazepine in somatic and visceral pain models in rodents. Anesth Analg 110: 1198-1205, 2010.

21. Tallarida RJ: Drug synergism: Its detection and applications. J Pharmacol Exp Ther 298: 865-872, 2001.

22. Tallarida RJ: The interaction index: A measure of drug synergism. Pain 98: 163-168, 2002.

23. Fürst $S$ : Transmitters involved in antinociception in the spinal cord. Brain Res Bull 48: 129-141, 1999.

24. Anker-Møller E, Spangsberg N, Arendt-Nielsen L, Schultz P, Kristensen MS and Bjerring P: Subhypnotic doses of thiopentone and propofol cause analgesia to experimentally induced acute pain. Br J Anaesth 66: 185-188, 1991.

25. Zacny JP, Coalson DW, Young CJ, Klafta JM, Lichtor JL, Rupani G, Thapar P and Apfelbaum JL: Propofol at conscious sedation doses produces mild analgesia to cold pressor-induced pain in healthy volunteers. J Clin Anesth 8: 469-474, 1996.

26. Briggs LP, Dundee JW, Bahar M and Clarke RS: Comparison of the effect of diisopropyl phenol (ICI 35,868) and thiopentone on response to somatic pain. Br J Anaesth 54: 307-311, 1982.

27. Wilder-Smith $\mathrm{OH}$, Kolletzki $\mathrm{M}$ and Wilder-Smith $\mathrm{CH}$ : Sedation with intravenous infusions of propofol or thiopentone Effects on pain perception. Anaesthesia 50: 218-222, 1995.

28. Goto T, Marota JJ and Crosby G: Pentobarbitone, but not propofol, produces pre-emptive analgesia in the rat formalin model. Br J Anaesth 72: 662-667, 1994.

29. Nadeson R and Goodchild CS: Antinociceptive properties of propofol: Involvement of spinal cord gamma-aminobutyric acid(A) receptors. J Pharmacol Exp Ther 282: 1181-1186, 1997.

30. Merrill AW, Barter LS, Rudolph U, Eger EI II, Antognini JF, Carstens MI and Carstens E: Propofol's effects on nociceptive behavior and spinal C-Fos expression after intraplantar formalin injection in mice with a mutation in the gamma-aminobutyric acid-type(A) receptor beta3 subunit. Anesth Analg 103: 478-483, 2006. 